\title{
Monosymptomatic Hypochondriacal Psychosis (somatic delusional disorder): A report of two cases
}

Historically, the term Monosymptomatic Hypochondriacal Psychosis (MHP) was first used by Munro in 1978. ${ }^{1}$ MHP is classified as a somatic type of delusional disorder in DSM- IV 2 and is defined as an erroneous conviction of bodily disease, abnormality or alteration. ${ }^{3}$ It includes delusional beliefs about bodily sensations or functions; such as feeling malodorous, being infected by parasites, having dysmorphic features, or that a certain organ is no longer functioning. ${ }^{4} \mathrm{MHP}$ has been divided into 4 main categories: Delusions of infestation (including parasitosis); delusions of dysmorphophobia, such as of misshapenness, personal ugliness, or exaggerated size of body parts (this seems closest to that of body dysmorphic disorder); delusions of foul body odours or halitosis or delusional bromosis (also known as olfactory reference syndrome); and a miscellaneous group. ${ }^{5}$

The term "monosymptomatic" does not imply the absence of symptoms of psychiatric disability other than the central delusion, rather that such symptoms occur as a psychological reaction to, or as a co-morbid disorder with, the primary psychotic or physical illness. . $^{3,9}$ The following two cases of MHP are presented to illustrate the psychosocial impact of the disorder, the treatment outcome, and to create awareness about this disorder among health care providers. The two patients gave informed consent for anonymous publication.

Miss A, a 29 year old single woman, presented with a year long history of third person auditory hallucinations, talking and laughing to herself, delusions of reference and a five month history of olfactory hallucinations of bad odour coming from her body and mouth and decline in personal hygiene. She withdrew from social activities, avoided interaction with people (including immediate family members), and stopped attending work. She became sad and wished herself dead but never attempted suicide and had no other symptoms suggestive of depressive illness. Her parents sought help from a traditional healer, visited two secondary health facilities, including a dental centre and the general out-patient department of our hospital from where she was referred to the psychiatrists.

This was her first episode but there was a history of mental illness in her maternal and paternal family. She was a university graduate and her inability to secure better employment (she was a primary school teacher) four years after her graduation was identified as a major psychosocial stressor that could have precipitated her illness. She was not

Correspondence

DrPO Ajiboye

email: poboye203@yahoo.com abusing any psychoactive substances and was said to be well adjusted premorbidly. Based on history and examination, she was managed as a case of paranoid schizophrenia (with olfactory reference syndrome) and was treated with haloperidol 15mg daily to which she responded positively after one week. As of when she was seen last in the out-patient clinic, she remained stable on maintenance dose of haloperidol $5 \mathrm{mg}$ nocte.

Mr B was a 45 year old married, Christian saw-miller who presented with a year and a half history of the feeling that insects were crawling all over his body, a mucus substance entering his eyes and a three month history of inadequate sleep. The insects were of different sizes and shapes (cubiodal and cylindrical). These insects produced different sensations and were more concentrated on the trunk and the pubic region. He believed that the crawling sensation was a sign that he had contracted Human Immunodeficiency Virus / Acquired immune Deficiency Syndrome (HIV/AIDS) because his symptoms started a month after he had sexual intercourse with a female friend. Following this, he stopped having sexual intercourse with his wife because he did not want to transfer the HIV/AIDS infection to her.

There were associated feelings of undue sadness, anhedonia, lack of energy, feelings of worthlessness and hopelessness, suicidal ideation (but no attempt), loss of appetite and poor sleep. He had stopped working because the noise from his machine made the insects more virulent. $\mathrm{He}$ had no perceptual abnormalities, other delusions or manic symptoms. He sought traditional help before consulting a physician who conducted numerous investigations, which were all negative, and referred him to the psychiatrists. This was his first episode of mental illness and there was no significant family history.

He was managed as a case of severe depression with psychotic features and delusions of insect infestation as a comorbid disorder. He was treated on an out- patient basis with Amitriptyline and Trifluoperazine. Eleven months after his initial presentation, he was brought by his neighbours on account of poor medication adherence, lack of improvement in his health and serious suicidal intent. He was admitted for one month and had six doses of electroconvulsive therapy (ECT), cognitive and supportive psychotherapy, and oral medication. He had improved on discharge but a few months later, he defaulted for a year to attempt a religious cure. When he resumed treatment, his condition had deteriorated and his medication was changed to a combination of sertraline and trifluoperazine with minimal improvement. Amitriptyline was recommenced for financial reasons. Despite improvement in 
sleep and suicidal ideation, the crawling sensation of insects on his body persists.

The sociodemographic variables of the two cases are consistent with previous reports that MHP has no predilection for any particular age, sex, racial or religious grouping, social class or intellectual level. ${ }^{3}$ It has been documented that when MHP occurs, it should be considered as a co-morbid condition or psychological reaction to a psychiatric or physical illness. ${ }^{3,6-9}$ Patients have a tendency to self medicate or seek help from non-psychiatric sources. They come to the attention of the psychiatric services only by referral from colleagues in other specialities. This also accounts for the apparent under estimation of MHP prevalence in the general population. ${ }^{3}$ Treatment response in the two described cases was very different, according to the literature, treatment outcome depends on the underlying aetiology, type of treatment, patient compliance, age of onset and chronicity of illness. ${ }^{6,10}$ Slow response of patients to treatment is a common finding. ${ }^{6}$

The two cases highlight that MHP can occur in response to, or co-morbid with, a primary psychotic or physical disorder, that it has significant psychosocial impact and causes considerable morbidity and it may not be as rare as presumed.

\section{PO Ajiboye, AD Yusuf}

Department of Behavioural Sciences, University of Ilorin, University of Ilorin Teaching Hospital, Ilorin, Kwara State, Nigeria

\section{References}

1. Munro A. Monosymptomatic hypochondriasis psychosis. Br J Hosp Med 1980; 24: 34-8.

2. American Psychiatric Association. Diagnostic and Statistical Manual of Mental Disorders- IV. Washington DC. American Psychiatric Association, 1994.

3. Reilly TM. Monosymptomatic hypochondriacal psychosis: Presentation and Treatment. Proc R Soc Med 1977; 70(suppl10): 39-43.

4. Roberts LW, Hoop JG, Heinrich TW. Delusional disorder In : Clinical Psychiatry Essentials 1st ed. Baltimore, Maryland; Lippincott Williams and Wilkins 2010: 175-76.

5. Sadock BJ, Sadock VA. Delusional disorder and shared psychotic disorder In: Kaplan and Sadock's Synopsis of psychiatry 10th ed. Philadelphia, PA; Lippincott Williams and Wilkins 2007: 509-510.

6. Aw DCW,Thong JY, Chan HL. Delusional parasitosis: Case series of 8 patients and review of literature. Ann Acad Med Singapore 2004; 33:89-94.

7. Bhatia MS, Jagawat T Choudlhary S. Delusionnal parasitosis: a clinical profile. Int J Psychiatry Med 2000; 30: 83-91.

8. Ait-Ameur A, Bern P, Firoloni MP, Menecier P. Delusional parasitosis or Ekbom's syndrome. La Rev Med Interne 2000; 21: 182-86.

9. Sugahara H, Otani Y, Sakamoto M. Delusional parasitosis accompanied by word deafness due to cerebral infarction: Folie a deux. Psychosomatics 2000; 41:447-8.

10. Srinivasan TN, Suresh TR, Jayaram V, FErnendez MP. Nature and treatment of delusional parasitosis: A different experience in India. Int J Dermatol 1994; 33:851-5. 